\title{
Influence of a D-aspartic Acid/Sodium Nitrate/Vitamin D3 Dietary Supplement on Physiological Parameters in Middle-aged Men: A Pilot Study
}

\author{
Richard J. Bloomer ${ }^{*}$, Trint A. Gunnels, Ryan G. Moran and JohnHenry M. Schriefer
}

Cardiorespiratory/Metabolic Laboratory, Department of Health and Sport Sciences, University of Memphis, Memphis, TN, USA

\begin{abstract}
D-aspartic acid (DAA), nitrate, and vitamin $\mathrm{D}_{3}$ have received considerable attention in recent years for their potential health-enhancing properties. Using an open-label design, we evaluated the impact of a DAA/sodium nitrate/ vitamin $\mathrm{D}_{3}$ dietary supplement on blood testosterone and nitrate/nitrite, as well as subjective indicators of health, in middle-aged men.
\end{abstract}

Methods: 10 overweight or obese men (mean age: 42 years) were assigned to ingest a DAA/sodium nitrate/ vitamin $\mathrm{D}_{3}$ supplement (either one or two servings per day) for 28 days. Blood total and free testosterone and nitrate/nitrite was measured before and after 14 and 28 days of supplementation. Subjective assessment of to health indicators (e.g., energy level, libido) was included at each collection time.

Results: Total and free testosterone increased on average 5-10\%, which was not of statistical significance $(\mathrm{p}>0.05)$. The response was highly variable; some men failed to respond to treatment, while men with relatively low basal testosterone values experienced increases exceeding 20\%. Plasma nitrate/nitrite was increased approximately 6-10 fold after treatment with the supplement, with a trend noted for a time effect $(\mathrm{p}=0.07)$. Men reported a significantly better feeling following supplement use, as evidenced by a time effect for both vitality $(\mathrm{p}=0.02)$ and libido $(\mathrm{p}=0.04)$, with a trend noted for increased energy level $(\mathrm{p}=0.08)$ and mental outlook and $\operatorname{mood}(\mathrm{p}=0.10)$.

Conclusion: Twenty-eight days of treatment with a DAA/sodium nitrate/ vitamin $\mathrm{D}_{3}$ dietary supplement increased blood nitrate/nitrite and improved subjective feelings of vitality and libido in middle-aged men. In selected men with low basal testosterone values, the supplement increased circulating levels of this hormone.

Keywords: D-aspartic acid, Dietary supplements, Libido, Sodium nitrate, Testosterone, Vitality.

\section{INTRODUCTION}

Dietary supplements aimed at improving subjective feelings of well-being in middle-aged and older men are of great interest. This may be partly related to the fact that decreased circulating testosterone is often associated with aging [1], coupled with the fact that variables regulating blood flow may be somewhat compromised by aging [2].

Related to the above, nutrients aimed at increasing circulating testosterone and improving systemic blood flow are of great interest. One ingredient that has received a great deal of attention recently for its purported ability to increase blood testosterone is D-aspartic acid (DAA). DAA is present in rat nervous system and endocrine glands, and has been shown to induce both growth hormone and luteinizing hormone release [3], while stimulating the release of sex hormones from the pituitary gland and testes in animals. For

*Address correspondence to the author at the Department of Health and Sport Sciences, 106 Roane Fieldhouse, The University of Memphis, Memphis, TN 38152, USA; Tel: 901-678-5638; Fax: 901-678-3591;

E-mail: rbloomer@memphis.edu example, the incubation of DAA with isolated rat testes has demonstrated an increased synthesis of testosterone [4], suggesting that DAA is involved in steroidogenesis. Additional studies involving rodents have found similar results $[5,6]$.

Much of the interest in DAA is based on the reported $42 \%$ increase in blood testosterone concentrations in young (27-37 year old) men following daily supplementation at $3120 \mathrm{mg}$ over the course of a 12 day period [6]. Having said that , both our lab (unpublished findings) and Willoughby and Leutholtz [7] have noted conflicting findings to those of Topo and colleagues; specifically, no increase in total or free testosterone when DAA is used by young men (mean age $\sim 24$ years old) with relatively high basal testosterone. Aside from this work, we are unaware of any human studies using DAA, despite animal studies demonstrating increases in testosterone with treatment $[4,6]$. It is possible that DAA is more helpful in middle-aged or older men, in particular those with low basal testosterone values. This question is partly the basis for the present pilot study. 
Beyond DAA, recent work has indicated an association between vitamin $D_{3}$ and circulating testosterone $[8,9]$. For example, Pilz and colleagues reported that 31 healthy, overweight men who were supplemented with approximately 3000 IU of vitamin D daily for one year had a significant increase in total, bioactive, and free testosterone levels [8]. Based on these findings, coupled with those indicating various health benefits of vitamin $\mathrm{D}_{3}$ supplementation [10], use of this nutrient may prove beneficial to men.

In addition to the use of DAA and vitamin $\mathrm{D}_{3}$ to elevate blood testosterone, is the impact of sodium nitrate to increase circulating levels of nitrate/nitrite in middle-aged men, and the potential for improved blood flow and related outcomes (e.g., enhanced energy levels). Indeed, dietary nitrate ingestion has been reported to aid cardiorespiratory and muscular endurance [11]. Specifically, investigators have used either sodium nitrate $(\sim 500 \mathrm{mg})$ or beetroot juice (containing nitrate at a dosage of approximately $500 \mathrm{mg}$ ) as an ergogenic aid, reporting improvements in exercise performance [12], in addition to a lowering in blood pressure [13]. It has been suggested that these effects may be mediated by an increase in nitric oxide (NO), which acts as a vasodilator to open vessels and allow for greater blood flow. In turn, greater oxygen and nutrient delivery to active tissues (i.e., skeletal muscle) may be observed, leading to enhanced feeling of energy and vitality.

Considering the above, the present pilot study sought to determine the influence of a 28 day treatment period of DAA/sodium nitrate/ vitamin $\mathrm{D}_{3}$ on subjective indicators of health in middle-aged men, as well as blood testosterone and nitrate/nitrite (the metabolites of nitric oxide).

\section{MATERIALS AND METHODOLOGY}

\section{Subjects}

A total of 10 physically active men completed this study. Subjects were not current smokers and were considered to be in good overall health, without a history of cardiovascular or metabolic disease (including hypertension). Subjects were not using hormonal replacement therapy or dietary supplements designed to increase hormone production; nor were subjects using dietary supplements containing nitrate. Subject characteristics are presented in Table 1. Health history, medication and dietary supplement usage, and physical activity questionnaires were completed by all subjects and reviewed by an investigator to determine eligibility. Subjects were informed of all procedures, potential risks, and benefits associated with the study through both verbal and written form. The study procedures were approved by the University Institutional Review Board (IRB) for Human Subjects Research. Subjects who completed the study were compensated $\$ 150$ for their time.

\section{Testing}

During the initial lab visit subjects completed all paperwork, inclusive of the informed consent form. Subjects' heart rate and blood pressure, height, weight, waist, and hip circumference were measured. Subjects were provided with food logs and instructions regarding how to complete these logs during the 48 hours before each test day. Subjects returned to the lab on three occasions (before supplementation, after 14 days of supplementation, and after 28 days of supplementation) to complete the assessments indicated below. On each occasion subjects reported to the lab following a minimum 10 hour overnight fast. Upon arrival, subjects rested quietly for 20 minutes while seated in a chair. Subjects then completed a questionnaire related to their perceived level of energy and associated variables. Their resting heart rate (via palpation of the radial artery) and blood pressure (via auscultation) was measured. A blood sample was taken and processed as described below. This concluded their participation for the assigned day.

\section{Supplementation}

Following the above assessments on day 1 , subjects were evenly assigned to either one or two servings per day of the supplement (D-Pol ${ }^{\mathrm{TM}}$; Purus Labs, Dallas, TX). The supplement contained DAA at a dosage of $3120 \mathrm{mg}$ and sodium nitrate at a dosage of $480 \mathrm{mg}$. The supplement also contained vitamin D3 at a dosage of 4000IU. The

Table 1. Characteristics of men assigned to one or two servings per day of the supplement.

\begin{tabular}{|l|c|c|}
\hline \multicolumn{1}{|c|}{ Variable } & One Serving (n=5) & Two Servings (n=5) \\
\hline \hline Age (years) & $40.8 \pm 1.0$ & $43.4 \pm 4.2$ \\
\hline Height $(\mathrm{cm})$ & $174.7 \pm 3.3$ & $181.0 \pm 2.1$ \\
\hline Body Weight $(\mathrm{kg})$ & $87.8 \pm 5.7$ & $101.6 \pm 4.3$ \\
\hline Body Mass Index $\left(\mathrm{kg} \cdot \mathrm{m}^{-2}\right)$ & $28.6 \pm 0.9$ & $31.1 \pm 1.5$ \\
\hline Waist Circumference (cm) & $93.0 \pm 2.6$ & $102.8 \pm 3.6$ \\
\hline Hip Circumference (cm) & $103.9 \pm 3.6$ & $110.3 \pm 2.1$ \\
\hline Waist:Hip & $0.90 \pm 0.03$ & $0.93 \pm 0.02$ \\
\hline Weekly Aerobic Training (hrs) & $1.8 \pm 0.8$ & $2.8 \pm 0.7$ \\
\hline Weekly Anaerobic Training (hrs) & $3.7 \pm 0.5$ & $1.9 \pm 0.8$ \\
\hline
\end{tabular}

Values are mean \pm SEM.

No differences of statistical significance noted between groups ( $p>0.05)$. 
supplement was provided in powder form and subjects were required to mix the powder (approximately 5 grams) in water (8-12 ounces) for consumption. Subjects assigned to one serving per day were instructed to consume their daily serving with breakfast. Subjects assigned to two servings per day were instructed to consume their daily servings with both breakfast and dinner. The supplement was provided to each subject in a container and produced under standard Good Manufacturing Practices by a dietary supplement contract manufacturer. Subjects' compliance to supplement intake was determined at $100 \%$, based on remaining powder left in the supplement containers upon return.

\section{Blood Collection and Analysis}

Venous blood samples $(\sim 15 \mathrm{~mL})$ were taken from subjects via needle and Vacutainer ${ }^{\circledR}$. Samples were collected before beginning supplementation (Pre) and after 14 and 28 days of supplementation. Following individual collection, samples were processed accordingly and the plasma and serum was stored at $-70{ }^{\circ} \mathrm{C}$ until analyzed. Samples for analysis of total testosterone (catalogue: TE187S), free testosterone (catalogue: FT178S), and estradiol (catalogue: ES180S) were analyzed in serum using enzyme linked immunosorbent assay (ELISA) procedures according to the instructions provided by the manufacturer (Calbiotech, Inc. Spring Valley, CA). Nitrate/nitrite was analyzed in plasma using a commercially available colorimetric assay kit (catalogue: 780001) according to the procedures provided by the manufacturer (Caymen Chemical, Ann Arbor, MI). Prior to each analysis, all samples were thawed and mixed thoroughly, then analyzed in duplicate.

\section{Questionnaire}

Due to the potential influence of circulating testosterone and NO on health-specific parameters, a questionnaire was designed by the investigators and completed by subjects on the morning of each test day. Using a scale of $1-5$, with 1 representing the lowest rating and 5 representing the highest rating, subjects rated a number of variables pertaining to overall health with regards to how they felt over the past two weeks.

\section{Dietary Intake and Physical Activity}

Subjects were instructed to consume their usual diet and to record dietary intake during the 48 hours prior to each test day. Detailed instructions for completing the records were provided to each subject and records were analyzed using nutritional software (Food Processor Pro; ESHA Research, Salem, OR). Subjects were instructed not to consume alcohol or caffeinated beverages or dietary supplements containing caffeine or other stimulants, during the 48 hours prior to each test day. In addition, subjects were asked not to engage in sexual activity or to perform strenuous physical activity for the 48 hours prior to each test day. Finally, subjects were asked to obtain at least 7 hours of sleep the night prior to teach test day.

\section{Statistical Analysis}

Data were analyzed using a 2 (condition) by 3 (day) analysis of variance (ANOVA). Tukey post-hoc testing was used as needed. The data are presented as mean \pm SEM. All analyses were performed using JMP statistical software. Statistical significance was set at $\mathrm{p} \leq 0.05$.

\section{RESULTS}

All 10 subjects successfully completed the four-week study. One additional subject started the study but failed to complete the final two weeks due to experiencing orthostatic hypotension. We are uncertain whether or not this was due to treatment with the supplement; however, since nitrate is known as a vasodilator, it is possible that the supplement contributed to this result. Data for this subject are not included here.

Subject characteristics were not different between groups ( $p>0.05)$, as can be viewed in Table 1. Subjects were in good overall health, although all subjects were either overweight or grade I obese based on BMI classification. Aside from a higher vitamin $C(p=0.03)$ and $E(p=0.01)$ intake in the one serving per day group, dietary intake was not different between groups or across time ( $>0.05$; Table 2). Resting heart rate was not different $(\mathrm{p}>0.05)$ but a time effect was noted for systolic blood pressure $(\mathrm{p}=0.04$; Table 3); groups

Table 2. Dietary data of men assigned to one or two servings per day of the supplement.

\begin{tabular}{|c|c|c|c|c|c|c|}
\hline Variable & $\begin{array}{c}\text { One Serving } \\
\text { Pre }\end{array}$ & $\begin{array}{c}\text { One Serving } \\
\text { Day } 14\end{array}$ & $\begin{array}{c}\text { One Serving } \\
\text { Day } 28\end{array}$ & $\begin{array}{c}\text { Two Servings } \\
\text { Pre }\end{array}$ & $\begin{array}{c}\text { Two Servings } \\
\text { Day } 14\end{array}$ & $\begin{array}{c}\text { Two Servings } \\
\text { Day } 28\end{array}$ \\
\hline Kilocalories & $2374 \pm 532$ & $2252 \pm 236$ & $2175 \pm 249$ & $2219 \pm 443$ & $2185 \pm 397$ & $2394 \pm 447$ \\
\hline Protein (grams) & $138 \pm 29$ & $134 \pm 20$ & $159 \pm 24$ & $92 \pm 17$ & $89 \pm 15$ & $140 \pm 35$ \\
\hline Carbohydrate (grams) & $281 \pm 103$ & $216 \pm 34$ & $222 \pm 26$ & $256 \pm 64$ & $261 \pm 48$ & $262 \pm 53$ \\
\hline Fat (grams) & $84 \pm 14$ & $94 \pm 9$ & $80 \pm 12$ & $91 \pm 20$ & $88 \pm 19$ & $111 \pm 23$ \\
\hline Vitamin $\mathrm{C}(\mathrm{mg})^{* *}$ & $209 \pm 126$ & $162 \pm 94$ & $152 \pm 51$ & $46 \pm 13$ & $46 \pm 17$ & $40 \pm 19$ \\
\hline Vitamin E (mg)** & $12 \pm 5$ & $5 \pm 1$ & $17 \pm 7$ & $5 \pm 2$ & $3 \pm 1$ & $3 \pm 1$ \\
\hline Vitamin A (RE) & $838 \pm 348$ & $746 \pm 226$ & $958 \pm 321$ & $436 \pm 142$ & $535 \pm 232$ & $425 \pm 129$ \\
\hline
\end{tabular}

Data are mean \pm SEM.

** Group effect for vitamin $\mathrm{C}(\mathrm{p}=0.03)$ and vitamin $\mathrm{E}(\mathrm{p}=0.01)$; One Serving > Two Servings.

No other differences of statistical significance noted $(\mathrm{p}>0.05)$.

Note: Values are for the 48-hour period immediately preceding each test day. 
Table 3. Resting heart rate and blood pressure of men assigned to one or two servings per day of the supplement.

\begin{tabular}{|c|c|c|c|c|c|c|}
\hline Variable & $\begin{array}{c}\text { One Serving } \\
\text { Pre }\end{array}$ & $\begin{array}{c}\text { One Serving } \\
\text { Day 14 }\end{array}$ & $\begin{array}{c}\text { One Serving } \\
\text { Day 28 }\end{array}$ & $\begin{array}{c}\text { Two Servings } \\
\text { Pre }\end{array}$ & $\begin{array}{c}\text { Two Servings } \\
\text { Day 14 }\end{array}$ & $\begin{array}{c}\text { Two Servings } \\
\text { Day 28 }\end{array}$ \\
\hline \hline HR (bpm) & $65.0 \pm 4.9$ & $61.2 \pm 1.6$ & $62.4 \pm 3.7$ & $64.2 \pm 2.9$ & $61.0 \pm 3.4$ & $62.2 \pm 2.3$ \\
\hline SBP $(\mathrm{mm} \mathrm{Hg})^{*}$ & $119.6 \pm 1.9$ & $118.6 \pm 1.5$ & $119.4 \pm 1.6$ & $124.8 \pm 1.5$ & $116.0 \pm 2.9$ & $118.4 \pm 1.0$ \\
\hline DBP $(\mathrm{mm} \mathrm{Hg})$ & $79.0 \pm 1.5$ & $80.8 \pm 0.8$ & $78.8 \pm 5.1$ & $85.0 \pm 1.6$ & $78.8 \pm 2.2$ & $81.2 \pm 2.9$ \\
\hline
\end{tabular}

Data are mean \pm SEM.

* Time effect for SBP ( $\mathrm{p}=0.04)$; groups combined, day 14 lower than Pre ( $\mathrm{p}=0.01)$; Two servings, day 14 ( $\mathrm{p}=0.002)$ and day 28 ( $\mathrm{p}=0.02)$ lower than Pre. No other differences of statistical significance noted $(\mathrm{p}>0.05)$.

Note: HR=Heart Rate; SBP = Systolic Blood Pressure; DBP = Diastolic Blood Pressure

Table 4. Perceived feelings of men assigned to one or two servings per day of the supplement.

\begin{tabular}{|c|c|c|c|c|c|c|}
\hline Variable & $\begin{array}{c}\text { One Serving } \\
\text { Pre }\end{array}$ & $\begin{array}{c}\text { One Serving } \\
\text { Day } 14\end{array}$ & $\begin{array}{c}\text { One Serving } \\
\text { Day } 28\end{array}$ & $\begin{array}{c}\text { Two Servings } \\
\text { Pre }\end{array}$ & $\begin{array}{c}\text { Two Servings } \\
\text { Day } 14\end{array}$ & $\begin{array}{c}\text { Two Servings } \\
\text { Day } 28\end{array}$ \\
\hline Alertness & $4.0 \pm 0.7$ & $4.2 \pm 0.4$ & $4.0 \pm 0.7$ & $3.8 \pm 1.1$ & $4.0 \pm 1.0$ & $4.2 \pm 0.8$ \\
\hline Energy Level $\uparrow$ & $3.6 \pm 0.5$ & $4.4 \pm 0.5$ & $4.2 \pm 0.4$ & $3.2 \pm 1.1$ & $4.0 \pm 1.0$ & $4.0 \pm 1.0$ \\
\hline Vitality* & $3.4 \pm 0.5$ & $4.4 \pm 0.5$ & $4.4 \pm 0.5$ & $3.2 \pm 1.1$ & $4.0 \pm 1.0$ & $4.2 \pm 0.8$ \\
\hline Workout Effectiveness & $3.8 \pm 0.4$ & $4.4 \pm 0.5$ & $4.2 \pm 0.4$ & $3.6 \pm 0.5$ & $4.0 \pm 1.0$ & $4.4 \pm 0.9$ \\
\hline Muscle Strength & $3.6 \pm 0.5$ & $4.2 \pm 0.4$ & $4.4 \pm 0.5$ & $3.8 \pm 0.4$ & $4.0 \pm 1.0$ & $4.0 \pm 1.0$ \\
\hline Muscle Endurance & $3.8 \pm 0.4$ & $4.0 \pm 0.7$ & $4.2 \pm 0.4$ & $3.4 \pm 0.5$ & $3.8 \pm 1.3$ & $4.2 \pm 1.1$ \\
\hline Sleep Quality & $3.6 \pm 0.5$ & $3.8 \pm 0.8$ & $4.0 \pm 0.7$ & $3.6 \pm 1.5$ & $4.0 \pm 1.4$ & $4.2 \pm 1.1$ \\
\hline
\end{tabular}

Data are mean \pm SEM.

* Time effect for vitality $(\mathrm{p}=0.02)$; Day $14(\mathrm{p}=0.02)$ and Day $28(\mathrm{p}=0.01)$ higher than Pre.

* Time effect for libido ( $\mathrm{p}=0.04)$; Day $14(\mathrm{p}=0.02)$ and Day $28(\mathrm{p}=0.04)$ higher than Pre.

No other differences of statistical significance noted $(\mathrm{p}>0.05)$.

$\uparrow$ Trend for time effect for energy level $(\mathrm{p}=0.08)$.

$\uparrow$ Trend for time effect for mental outlook $\& \operatorname{mood}(\mathrm{p}=0.10)$.

Note: Using a rating of 1-5, with 1 representing the lowest rating and 5 representing the highest rating, subjects were asked to rate each variable in the above table, with consideration of how they felt during the prior two weeks.

combined, day 14 lower than Pre; Two servings, day 14 and day 28 lower than Pre.

With regards to subjects' perceived feelings associated with use of the supplement, a time effect was noted for vitality $(\mathrm{p}=0.02)$ and libido $(\mathrm{p}=0.04)$, with day 14 and day 28 higher than Pre (Table 4). Trends for a time effect were noted for energy level $(\mathrm{p}=0.08)$ and mental outlook and $\operatorname{mood}(\mathrm{p}=0.10)$.

No differences of statistical significance were noted for blood testosterone or estradiol ( $p>0.05$; Table 5). Of the five men assigned to one serving per day of the supplement, three experienced an increase in both total and free testosterone. Of the five men assigned to two servings per day of the supplement, two experienced an increase in both total and free testosterone. A post-hoc power analysis indicated that approximately 180 men would be needed to observe a statistically significant effect for testosterone.
A trend for a time effect was noted for nitrate/nitrite $(\mathrm{p}=0.07$; Table 5), with values increasing 6-10 fold following treatment with the supplement. With the exception of one subject assigned to one serving per day of the supplement, all men experienced an increase in nitrate/nitrite. A post-hoc power analysis indicated that approximately 30 men would be needed to observe a statistically significant effect for nitrate/nitrite.

\section{DISCUSSION}

Findings from the present study indicate that daily ingestion of a DAA/sodium nitrate/ vitamin $\mathrm{D}_{3}$ supplement for 28 days resulted in an increase in blood nitrate/nitrite and improved subjective feelings of vitality and libido in middleaged men, with a trend for improving energy levels and mental outlook and mood. In approximately $50 \%$ of men, the supplement increased circulating levels of testosterone. 
Table 5. Biochemical data of men assigned to one or two servings per day of the supplement.

\begin{tabular}{|c|c|c|c|c|c|c|}
\hline Variable & $\begin{array}{c}\text { One Serving } \\
\text { Pre }\end{array}$ & $\begin{array}{c}\text { One Serving } \\
\text { Day 14 }\end{array}$ & $\begin{array}{c}\text { One Serving } \\
\text { Day 28 }\end{array}$ & $\begin{array}{c}\text { Two Servings } \\
\text { Pre }\end{array}$ & $\begin{array}{c}\text { Two Servings } \\
\text { Day 14 }\end{array}$ & $\begin{array}{c}\text { Two Servings } \\
\text { Day 28 }\end{array}$ \\
\hline \hline Testosterone Total $\left(\mathrm{ng} \cdot \mathrm{mL}^{-1}\right)$ & $2.6 \pm 0.1$ & $2.7 \pm 0.3$ & $2.9 \pm 0.4$ & $2.9 \pm 0.3$ & $3.4 \pm 0.3$ \\
\hline Testosterone Free $\left(\mathrm{pg} \cdot \mathrm{mL}^{-1}\right)$ & $4.4 \pm 0.3$ & $4.3 \pm 0.2$ & $4.6 \pm 0.4$ & $4.0 \pm 0.3$ & $4.2 \pm 0.5$ & $4.3 \pm 0.6$ \\
\hline Estradiol $\left(\mathrm{pg} \cdot \mathrm{mL}^{-1}\right)$ & $63.7 \pm 6.6$ & $65.3 \pm 7.4$ & $67.7 \pm 7.6$ & $62.0 \pm 5.3$ & $66.9 \pm 7.1$ & $64.1 \pm 4.3$ \\
\hline Nitrate/Nitrite† $\left(\mu \mathrm{mol} \cdot \mathrm{L}^{-1}\right)$ & $27.1 \pm 2.6$ & $163.4 \pm 65.0$ & $108.0 \pm 68.4$ & $20.5 \pm 1.4$ & $94.4 \pm 32.6$ & $213.2 \pm 104.5$ \\
\hline
\end{tabular}

Data are mean \pm SEM.

No differences of statistical significance noted $(\mathrm{p}>0.05)$

$\dagger$ Trend for time effect for Nitrate/Nitrite $(\mathrm{p}=0.07)$.

These findings are in reference to a sample of middle-aged, overweight or obese men.

Perhaps most importantly, our findings indicate that men ingesting the DAA/sodium nitrate/ vitamin $\mathrm{D}_{3}$ supplement reported improvements in multiple subjective measures of physical and mental health, including vitality, libido, energy, and mental outlook and mood (Table 4). These findings were commonplace across our subjects, suggesting that the supplement may be responsible for improving the general outlook of middle-aged men with regards to these variables. Of course, since this was an open label study, it is possible that subjects were influenced by the placebo effect [14]. Additional, placebo controlled studies are needed using the supplement in a sample of middle-aged men to replicate the present findings.

It is possible that the enhanced feelings noted were due in part to the large increase in circulating NO metabolites (nitrate/nitrite). The supplement resulted in an approximate 6-10 fold increase in nitrate/nitrite following treatment, which is far larger than the increase observed with any other dietary ingredient/supplement that we have reviewed. In fact, in another pilot experiment in our lab using a sample of five men (mean age: 29 years) who ingested one serving of the supplement, plasma nitrate/nitrite was noted to be increased approximately 10-fold above baseline when measured just one hour following ingestion (unpublished findings). While this increase is massive, we are uncertain of the physiologic relevance of this change. It is possible that this increase is representative of an increase in NO within the vasculature, potentially influencing vascular homeostasis [15]. This would partly explain subjects' ratings of improved energy and associated variables, with treatment.

The increase in nitrate/nitrite, representative of NO, may be responsible for the reduction in blood pressure noted with supplementation-in particular within the two servings per day group (Table 3). Considering that men in this study were normotensive, it is certainly plausible to hypothesize that men with hypertension may have responded to a greater extent with treatment. Prior work involving nitrate ingestion has noted blood pressure reduction [16], with the present study confirming these findings in a group of normotensive men. Based on the potential influence of nitrate ingestion on blood pressure, care should be taken when dosing subjects with nitrate, as too high of a dosage may result in too significant a reduction in blood pressure. Additional work is needed to determine the optimal dosage of nitrate for purposes of blood pressure control.

Past work involving DAA supplementation has yielded mixed findings with regards to increasing circulating testosterone. Topo and colleagues noted an approximate $42 \%$ increase in total testosterone following 12 days of DAA supplementation in young (aged 27-37 years) men-a finding that was observed in 20 out of 23 subjects [6]. More recently, Willoughby and Leutholtz reported that the same dosage of DAA ( $\sim 3$ grams) taken for a 28 day period failed to increase total or free testosterone in young (aged 18-23 years) men [7]. We have recently noted similar findings as Willoughby and Leutholtz, of no increase in total or free testosterone when 24 young men ingested 3 grams daily of DAA (unpublished findings). We believe that the age and basal testosterone values of subjects may be responsible for the discrepancy in findings. For example, our prior work sample consisted of a group of young men between the ages of 18-39 years whose total testosterone levels were in the mid or high range of "normal" (mean: $6.2 \mathrm{ng} \cdot \mathrm{mL}^{-1}$ ); considering the normal range of $\sim 3-9 \mathrm{ng} \cdot \mathrm{mL}^{-1}$ [17]. Subjects in the study of Willoughby and Leutholtz [7] were also young (18-23 years), with a mean basal total testosterone value of $8.1 \mathrm{ng} \cdot \mathrm{mL}^{-1}$. This is compared to subjects in the study of Topo and colleagues [6], who ranged in age from 27 to 37 years and had a mean basal testosterone value of $4.5 \mathrm{ng} \cdot \mathrm{mL}^{-1}$. The lower mean basal testosterone value of subjects in the Topo et al. study could have been responsible for the differing findings for testosterone elevation with DAA treatment. Considering the low mean basal testosterone values of subjects in the present study (e.g., $\sim 3 \mathrm{ng} \cdot \mathrm{mL}^{-1}$ ), it is not surprising that we observed a small increase in this measure, with some subjects who were very low to begin with experiencing a more pronounced effect with DAA treatment. More work is needed to determine if DAA supplementation is beneficial for men with depressed basal testosterone concentrations.

Aside from the focus on testosterone, reports from animal models indicate that DAA may lead to an increase in estradiol-a result of increased aromatase activity and the conversion of testosterone to estradiol [18-20]. A lack of increase in estradiol has been noted following DAA supplementation in the work of Willoughby and Leutholtz [7], as well as in our recent work (unpublished findings). The present data extend those findings, noting minimal change in 
estradiol, even with 6 grams daily of DAA over a four week period.

\section{CONCLUSION}

In summary, twenty-eight days of treatment with a DAA/sodium nitrate/ vitamin $\mathrm{D}_{3}$ dietary supplement increases blood nitrate/nitrite and can improve subjective feelings of vitality and libido in middle-aged men. In men with low basal testosterone values, the supplement may increase circulating levels of this hormone. Additional work is needed, using a placebo controlled design and a larger sample of men, to more fully elucidate the role of DAA/nitrate/ vitamin $\mathrm{D}_{3}$ to improve selected measures of health in middle-aged to older men.

\section{CONFLICT OF INTEREST}

Funding for this work was provided in part by Formulife, Inc. RJ Bloomer has been a principal investigator on research projects and a consultant to dietary ingredient and supplement companies. No other author declares any conflict of interest.

\section{ACKNOWLEDGMENTS}

Funding for this work was provided in part by Formulife, Inc. and the University of Memphis. The authors acknowledge the assistance of Ramzi Majaj in performing the dietary analysis.

\section{REFERENCES}

[1] Miner M, Barkin J, Rosenberg MT. Testosterone deficiency: myth, facts, and controversy. Can J Urol 2014; 21 Suppl 2: 39-54.

[2] Djuric D, Popovic Z, Petrovic J, Bojic M. Age-related progressive brachial artery endothelial dysfunction precedes the changed carotid and left ventricular geometry in healthy humans. Angiology 1999; 50(7): 555-61.

[3] D'Aniello A, Di Fiore MM, Fisher GH, et al. Occurrence of Daspartic acid and N-methyl-D-aspartic acid in rat neuroendocrine tissues and their role in the modulation of luteinizing hormone and growth hormone release. FASEB J 2000; 14(5): 699-714.

[4] D'Aniello A, Cosmo AD, Cristo CD. et al. Involvement of Daspartic acid in the synthesis of testosterone in rat testes. Life Sci 1996; 59: 97-104.
[5] Nagata Y, Homma H, Lee J, Imai K. D-Aspartate stimulation of testosterone synthesis in rat Leydig cells. FEBS Lett 1999; 444: 160-164.

[6] Topo E, Soricelli A, D'Aniello A, et al. The role and molecular mechanism of D-aspartic acid in the release and synthesis of LH and testosterone in humans and rats. Reprod Biol Endocrinol 2009; 7: 120 .

[7] Willoughby DS, Leutholtz B. D-aspartic acid supplementation combined with 28 days of heavy resistance training has no effect on body composition, muscle strength, and serum hormones associated with the hypothalamo-pituitary-gonadal axis in resistance-trained men. Nutr Res 2013; 33(10): 803-10.

[8] Pilz S, Frisch S, Koertke H, et al. Effect of vitamin D supplementation on testosterone levels in men. Horm Metab Res 2011; 43: 223-225.

[9] Wehr E, Pilz S, Boehm BO, et al. Association of vitamin D status with serum androgen levels in men. Clin Endocrinol (Oxf) 2010; 73: $243-248$

[10] Pilz S, Gaksch M, Hartaigh BÓ, Tomaschitz A et al. Vitamin D in Preventive Medicine. Anticancer Res 2015; 35(2): 1161-1170.

[11] Jones AM, Vanhatalo A, Bailey SJ. Influence of dietary nitrate supplementation on exercise tolerance and performance. Nestle Nutr Inst Workshop Ser 2013; 75: 27-40.

[12] Jones AM. Dietary nitrate supplementation and exercise performance. Sports Med 2014; 44 Suppl 1: S35-45.

[13] Jajja A, Sutyarjoko A, Lara J, et al. Beetroot supplementation lowers daily systolic blood pressure in older, overweight subjects. Nutr Res 2014; S0271-5317(14): 00192-4.

[14] Požgain I, Požgain Z, Degmečić D. Placebo and nocebo effect: a mini-review. Psychiatr Danub 2014; 26(2): 100-7.

[15] Carlström M, Liu M, Yang T, et al. Cross-talk Between NitrateNitrite-NO and NO synthase pathways in control of vascular NO homeostasis. Antioxid Redox Signal 2014 Feb 6. [Epub ahead of print]

[16] Siervo M, Lara J, Ogbonmwan I, Mathers JC. Inorganic nitrate and beetroot juice supplementation reduces blood pressure in adults: a systematic review and meta-analysis. J Nutr 2013; 143(6): 818-26.

[17] Rhoden EL, Morgentaler A. Risks of testosterone-replacement therapy and recommendations for monitoring. N Engl J Med 2004; 350: 482-492.

[18] Assisi, L, Botte, V, D'Aniello, A, Di Fiore, MM. Enhancement of aromatase activity by D-aspartic acid in the ovary of the lizard Podarcis s. sicula. Reproduction 121: 803-808, 2001.

[19] Lamanna, C, Assisi, L, Botte, V, Di Fiore, MM. Endogenous testicular D-aspartic acid regulates gonadal aromatase activity in boar. J Endocrinol Invest 29: 141-146, 2006.

[20] Lamanna, C, Assisi, L, Botte, V, Di Fiore, MM. Involvement of DAsp in P450 aromatase activity and estrogen receptors in boar testis. Amino Acids 32: 45-51, 2007. 